\title{
Evaluation of the Antimicrobial and Antioxidant Efficacy of Biogenic Chitosan synthesized from the Prawn Exoskeleton
}

\author{
N. Sundaramoorthy ${ }^{1}$, G. Ramya ${ }^{2}$, V. Satheeshwari ${ }^{2}$, J. Janani ${ }^{2}$, \\ A. Parkavi ${ }^{2}$, J. Hemapriya ${ }^{3}$ and S. Vijayanand ${ }^{2} *$

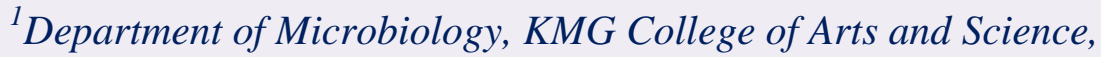 \\ Gudiyatham, Tamilnadu, India \\ ${ }^{2}$ Department of Biotechnology, BRT Lab, Thiruvalluvar University, Vellore, Tamilnadu, India \\ ${ }^{3}$ Department of Microbiology, DKM College for Women, Vellore, Tamilnadu, India \\ *Corresponding author
}

\section{A B S T R A C T}

Keywords

Chitosan,

Antimicrobial,

Antioxidant, Prawn

shell, DPPH Assay

Article Info

Accepted:

25 December 2020

Available Online:

10 January 2021
Chitosan is a polysaccharide biopolymer that combines a unique set of versatile physicochemical and biological characteristics which allow for a wide range of applications. Exoskeleton of prawn was powdered and subjected for sequential treatment process including deproteinization, demineralization and decolorization to obtain chitin in a colorless white powder form. The obtained chitin was subjected for deacetylation to obtain chitosan. The resultant biogenic chitosan was subjected for antibacterial and antifungal activity. Chitosan exhibited significant activity against Escherichia coli and Aspergillus niger. Free radical scavenging activity of chitosan gradually increased with increase in the concentration of chitosan. Antioxidant activity of prawn shell chitosan was found to be maximized at the concentration of $500 \mu \mathrm{l} / \mathrm{ml}$.

\section{Introduction}

Professor Henri Braconnot, Director of the Botanical Gardens at the Academy of Sciences in Nancy, France was the first to discover chitin in mushrooms in 1811. The English word "chitin" is derived from the French word "chitine," and the Latin word "chitōn," meaning mollusk. Chitin is the second most abundant natural polymer after cellulose. Chitosan is produced from chitin, which is a natural polysaccharide found in crab, shrimp, lobster, coral, jellyfish, butterfly, ladybug, mushroom and fungi. However, marine crustacean shells are widely used as primary sources for the production of chitosan (Madhavan et al., 1974; Shahidi et al., 2005). The waste from crab and shrimp processing 
has recently become a serious issue in coastal areas. Selective isolation of bioactive material from these wastes not only decrease the environmental pollution, but also increases the potential applications of chitosan in the field such as textiles, photography, medicine, agriculture, food processing etc.

Chitin and chitosan are an important family of high-molecular-weight linear polycationic heteropolysaccharides comprising copolymers of $\quad \beta$ - $(1 \rightarrow 4)$-2-acetamido-2-deoxy- $\beta$-Dglucopyranose (GlcNAc) and 2- amino-2deoxy- $\beta$-D-glucopyranose $(\mathrm{GlcN})$ units. The term chitosan describes a heterogeneous group of polymers differing in molecular weight, viscosity, degree of deacetylation, $\mathrm{pKa}$, etc. (Singla and Chawla, 2001). Chitin accommodates some valuable amount of protein and calcium salts. Chemical treatment involved in converting chitin to chitosan includes decalcification, deproteniation, decolourization and deacetylation (Ahamed et al., 2018). Chitosan has received great attention due to its cationic character (Anand et al., 2018). Chitosan is commercially produced on a large scale in different parts of the world (India, North America, Japan, Poland, Italy, Russia and Norway) (Singla and Chawla, 2001). It has been estimated that up to $10^{9}$ to $10^{10}$ tons of chitosan are annually produced in nature (Peter, 1997). Much of the commercial interest in chitosan arises from the fact that it combines unique biological characteristics which embark chitosan a very attractive biomaterial for a wide array of applications in the biomedical field, including being nontoxic, mucoadhesive, hemocompatible, biodegradable, and possessing antitumor, antioxidant, and antimicrobial properties (Ahmed and Ikram, 2015).

The alarming commercial and industrial exploitation of chitosan has peaked over the last 2 decades; it has emerged as a novel biomaterial in wastewater purification, food industries, medical and pharmaceutical industries, textile industries, agricultural, chemical, cosmetics, metal extraction and recovery, biochemical and biomedical engineering industries (Babel and Kurniawan, 2003; Doares et al., 1995; Takai et al., 2002). Chitosan and its derivatives have attracted much attention as antimicrobial agents and as elicitors of plant defense mechanisms (Muzzarelli et al., 1990; Rabea et al., 2003; Raafat et al., 2008.). In fact, a number of commercial applications of chitosan benefit from its antimicrobial activity, including its use in food preservation, manufacture of wound dressings and antimicrobial-finished textiles (Raafat et al., 2008). In view of the potential applications of chitosan in various fields, the present study is intended to evaluate the antimicrobial activity of chitosan against the selected bacterial and fungal pathogens and to access the antioxidant property of chitosan.

\section{Materials and Methods}

\section{Sample Collection and processing}

The fresh prawn samples were collected from local market located at Vellore, Tamil nadu, India. The shells (exoskeleton) were separated from the head and legs. The collected prawn exoskeleton was then washed several times with tap water to misplace residual tissues. Sample was stored in sterile zip lock bags and refrigerated overnight. Then the sample was dried in hot air oven at $60{ }^{\circ} \mathrm{C}$ for $24 \mathrm{~h}$. The dried sample was then ground to obtain fine powder that can pass through a 0.3-0.5 mm sieve. The sample was stored in a closed container for future use.

\section{Preparation of Biogenic Chitosan}

The following 3 steps, namely Deproteinization, Demineralization and 
Deacetylation were carried out sequentially for the preparation of biogenic chitosan.

\section{Deproteinization}

The exoskeleton samples of the prawn were placed in $250 \mathrm{ml}$ beaker and treated in boiling sodium hydroxide $(4 \% \mathrm{v} / \mathrm{v})$ for one hour in order to dissolve the proteins and sugars to isolate the crude chitin. After an hour of boiling in the sodium hydroxide, the beakers containing the prawn shell samples were removed from the hot plate, placed in the hood and allowed to cool for 30 minutes at room temperature.

\section{Demineralization}

Approximately $25 \mathrm{~g}$ of prawn's exoskeleton samples were demineralized with $100 \mathrm{ml}$ of HCL (1.0\%). The samples were allowed to soak for $24 \mathrm{~h}$ to remove minerals (mainly calcium carbonate). The demineralized prawn shell samples were then treated with $50 \mathrm{ml}$ of $20 \% \mathrm{NaOH}$ solution for one hour to decompose the albumin into water soluble amino acids. The remaining chitin was washed with deionized water, which was then drained off.

\section{Decolorization (DC) of Crude Chitin}

The deproteinated and demineralized shells were then placed in a $250 \mathrm{ml}$ beaker and treated with $100 \mathrm{ml}$ of $0.315 \% \mathrm{NaOCl}$ at 25 ${ }^{\circ} \mathrm{C}$ and shaken at $35 \mathrm{rpm}$ for $1 \mathrm{~h}$ to remove the carotenoid - Astaxanthin. The chitin was then washed with distilled water to remove the excess $\mathrm{NaOCl}$. The chitin was then dried at 60 ${ }^{\circ} \mathrm{C}$ for $24 \mathrm{~h}$ and weighed.

\section{Deacetylation of Chitin into Chitosan}

The deacetylation process was carried out by adding $100 \mathrm{ml}$ of $50 \% \mathrm{NaOH}$ to the chitin sample and then boiled at $100{ }^{\circ} \mathrm{C}$ for $2 \mathrm{~h}$ on a hot plate. The sample was then placed under the hood and cooled for $30 \mathrm{~min}$ at room temperature. Then the samples were washed continuously with $50 \% \mathrm{NaOH}$ and filtered in order to retain the solid matter, the chitosan. The prepared chitosan was then placed in 250 $\mathrm{ml}$ beaker and left uncovered and oven dried at $120{ }^{\circ} \mathrm{C}$ for $24 \mathrm{~h}$. The resultant chitosan will be creamy-white in color.

\section{Antimicrobial Activity of Chitosan by Well Diffusion Method}

\section{Preparation of Chitosan Solution}

Chitosan (DD 75\%) was prepared from prawn shell waste. In the preparation of chitosan solution, $2.4 \%(\mathrm{w} / \mathrm{v})$ chitosan were dispersed in a $1.0 \%(\mathrm{v} / \mathrm{v})$ acetic acid. After stirring overnight, the solution was autoclaved at $120^{\circ} \mathrm{C}$ for $15 \mathrm{~min}$.

\section{Bacterial strains used}

Gram positive bacterial strain, Staphylococcus aureus and gram negative bacterial strains viz, Escherichia coli, Klebsiella sp., Proteus sp., and Pseudomonas sp. were used for antimicrobial assay. The above mentioned bacterial strains were incubated in Nutrient Broth medium and incubated at $37{ }^{\circ} \mathrm{C}$ for 24 h. The overnight broth culture was used for investigating the antibacterial activity of chitosan.

\section{Fungal cultures used}

The fungal culture including Aspergillus niger, Aspergillus flavus, Aspergillus fumigatus, Rhizopus sp., and Candida sp., were used for antimicrobial assay. The selected culture was incubated in Potato Dextrose Broth (PDA) at room temperature. The overnight broth culture was used for investigating the antifungal activity of chitosan. 


\section{Antibacterial Activity of Chitosan Solution}

$0.1 \mathrm{ml}$ of overnight NA broth culture of the test organisms (Staphylococcus aureus, Escherichia coli, Klebsiella sp., Proteus sp. and Pseudomonas sp.) were firmly seeded over the Mueller-Hiton Agar (MHA) plates. Well of $6 \mathrm{~mm}$ diameter was punched over the agar plate using a sterile cork borer. Using micropipette, $100 \mu \mathrm{l}$ of chitosan solutions was added to well in the plate. These plates were then kept at low temperature $\left(4^{\circ} \mathrm{C}\right)$ for 24 hours and incubated at $37{ }^{\circ} \mathrm{C}$ for $24 \mathrm{~h}$. Following incubation period, formation of zone around the wells, confirmed the antibacterial activity of chitosan.

\section{Antifungal Activity of Chitosan Solution}

$0.1 \mathrm{ml}$ of PD broth culture of test organisms (Aspergillus niger, Aspergillus flavus, Aspergillus fumigatus, Rhizopus sp., and Candida sp.) were firmly seeded over the Potato Dextrose Agar (PDA) plate. Wells of 6 $\mathrm{mm}$ diameter was punched over the agar a plate using a sterile cork borer.

Using micropipette, $100 \mu \mathrm{l}$ of chitosan solutions was added to well in the plate. These plates were incubated at room temperature. Following incubation period, formation of zone around the well, confirmed the antifungal activity of chitosan.

\section{Antioxidant Property of Prawn Shell Chitosan by DPPH Assay}

Antioxidant property of the prawn shell chitosan was determined by DPPH assay. $1 \mathrm{ml}$ of $0.1 \mathrm{mM}$ DPPH in ethanol was prepared.

To that, the prawn shell chitosan varying in concentration from $100-500 \mu \mathrm{l}, 1 \mathrm{ml}$ ethanol and $0.95 \mathrm{ml}$ Tris HCL was added. The mixture was kept for 30 minutes and the absorbance was measured at $517 \mathrm{~nm}$ (Rushender et al.,
2012). The DPPH free radical scavenging activity was subsequently calculated.

$$
\text { DPPH Radical Scavenging }=\frac{\text { Control OD }- \text { Sample OD }}{\text { Control OD }} \times 100
$$

\section{Results and Discussion}

Chitin is a polysaccharide of animal origin found abundantly in nature and characterized by a fibrous structure. It forms the basis of the main constituent of the outer skeleton of insects and crustaceans like shrimp, crabs and lobster.

Chitosan is a versatile material with proved antimicrobial activity. Both chitin and chitosan is considered as antimicrobial compound against a number of target organisms including bacteria, fungi and algae (Goy et al., 2009).

Generally chitosan is contemplate to be bacteriostatic (prevent the growth of bacteria). Chitosan compound is used in all types of dressing and surgical sutures, dental implants, rebuilding bones and gums. It is also helpful in kidney failure and it binds with toxins in the digestive tract thereby leading to their excretion (Kim et al., 2009).

\section{Extraction of Chitin and Chitosan from Prawn Exoskeleton}

Exoskeleton of prawn was selected and washed with distilled water. The prawn shells were fragmented and ground into course powder.

Prawn shell powder was subjected for sequential treatment process including deproteinization, demineralization and decolorization to obtain chitin in a colorless white powder form. The obtained chitin was subjected for deacetylation to obtain chitosan powder (Fig. 1). 
Antimicrobial Activity of Chitosan by Well Diffusion Method

\section{Antibacterial Activity of Chitosan Solution}

Chitosan sample extracted from prawn shell exhibited significant activity against Escherichia coli $(24 \mathrm{~mm})$ which was followed by Proteus sp. $(18 \mathrm{~mm})$, Klebsiella sp. (15 $\mathrm{mm}$ ) and Staphylococcus aureus (12 $\mathrm{mm})$.

Among the tested isolates, Pseudomonas sp. exhibited remarkable resistance (Table 1). In addition, chitosan solution has been shown to inhibit the growth of Xanthomonas sp., which is pathogenic to Euphorbia pulcherrima (Li et al., 2008).

The mechanism antimicrobial activity of chitin and its derivatives has yet to be totally uncovered. In fact there are several proposed mechanisms. One of them is the ability of chitin and its derivatives to activate defense mechanisms of the host organisms (El Ghaouth et al., 1992) such as inducing the accumulation of chitinases and other pathogenesis-related proteins.

Another one is leakage in the cell wall of bacteria due to the interaction between positively charged chitosan molecules and the negatively charged surface of the bacteria (Young et al., 1982).

The chelating activity of chitosan has often been implicated as a possible mode of action
(Rabea et al., 2003). Chelation of metals does not seem to be of importance for the antibiotic activity of chitosan; in contrast, the formation of complexes with metal ions appears to abrogate this activity. Wydro et al., (2007) demonstrated that there are significant electrostatic and hydrophobic interactions, as well as hydrogen bonds between lipids and chitosan.

Binding of chitosan to cell wall polymers would trigger secondary cellular effects: destabilization and subsequent disruption of bacterial membrane function occur.

In addition, membrane-bound energy generation pathways are affected, probably due to impairment of the proper functional organization of the electron transport chain, thus interfering with proper oxygen reduction and forcing the cells to shift to anaerobic energy production. This might ultimately lead to dysfunction of the whole cellular apparatus (Raafat et al., 2008).

\section{Antifungal Activity of chitosan solution}

Antifungal activity of chitosan extract from prawn shell was comparatively investigated. Chitosan exhibited significant antagonistic activity against Aspergillus niger $(21 \mathrm{~mm})$, when compared to the rest all tested (i.e.,) Aspergillus flavus $(17 \mathrm{~mm})$, Aspergillus fumigatus $(19 \mathrm{~mm})$, Rhizopus $\mathrm{sp} .(15 \mathrm{~mm})$ and Candida sp. (14 mm) (Table 2).

Table.1 Antibacterial activity of chitosan sample

\begin{tabular}{|c|c|c|}
\hline S.No & $\begin{array}{c}\text { Bacterial strains } \\
\text { tested }\end{array}$ & Zone of inhibition $(\mathbf{m m})$ \\
\cline { 3 - 3 } & Chitosan \\
\hline 1. & Staphylococcus aureus & $12 \mathrm{~mm}$ \\
\hline 2. & Escherichia coli & $24 \mathrm{~mm}$ \\
\hline 3. & Proteus sp. & $18 \mathrm{~mm}$ \\
\hline $\mathbf{4 .}$ & Pseudomonas $\mathrm{sp}$. & $08 \mathrm{~mm}$ \\
\hline $\mathbf{5 .}$ & Klebsiella sp. & $15 \mathrm{~mm}$ \\
\hline
\end{tabular}


Table.2 Antifungal activity of chitosan sample

\begin{tabular}{|c|c|c|}
\hline S.No & Fungal strains tested & Zone of inhibition (mm) \\
\cline { 3 - 3 } & & Chitosan \\
\hline $\mathbf{1 .}$ & Aspergillus niger & $21 \mathrm{~mm}$ \\
\hline $\mathbf{2 .}$ & Aspergillus flavus & $17 \mathrm{~mm}$ \\
\hline $\mathbf{3 .}$ & Aspergillus fumigatus & $19 \mathrm{~mm}$ \\
\hline $\mathbf{4 .}$ & Rhizopus $\mathrm{sp}$ & $15 \mathrm{~mm}$ \\
\hline $\mathbf{5 .}$ & Candida $\mathrm{sp}$ & $14 \mathrm{~mm}$ \\
\hline
\end{tabular}

Fig.1 Powered form of biogenic chitosan prepared from prawn's exoskeleton

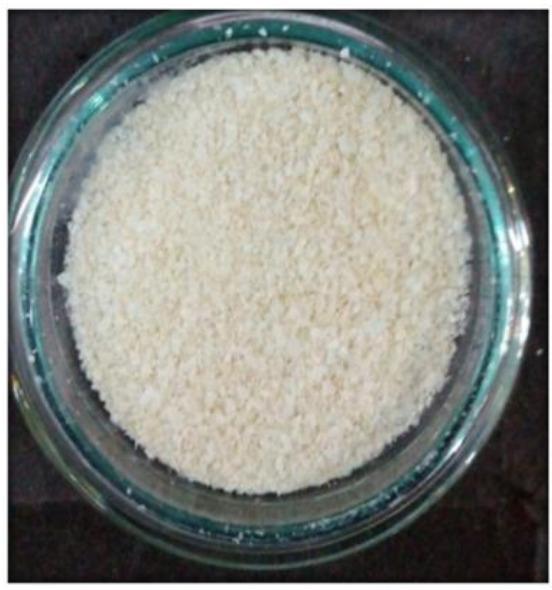

Fig.2 Antioxidant activity - DPPH Assay of biogenic chitosan sample

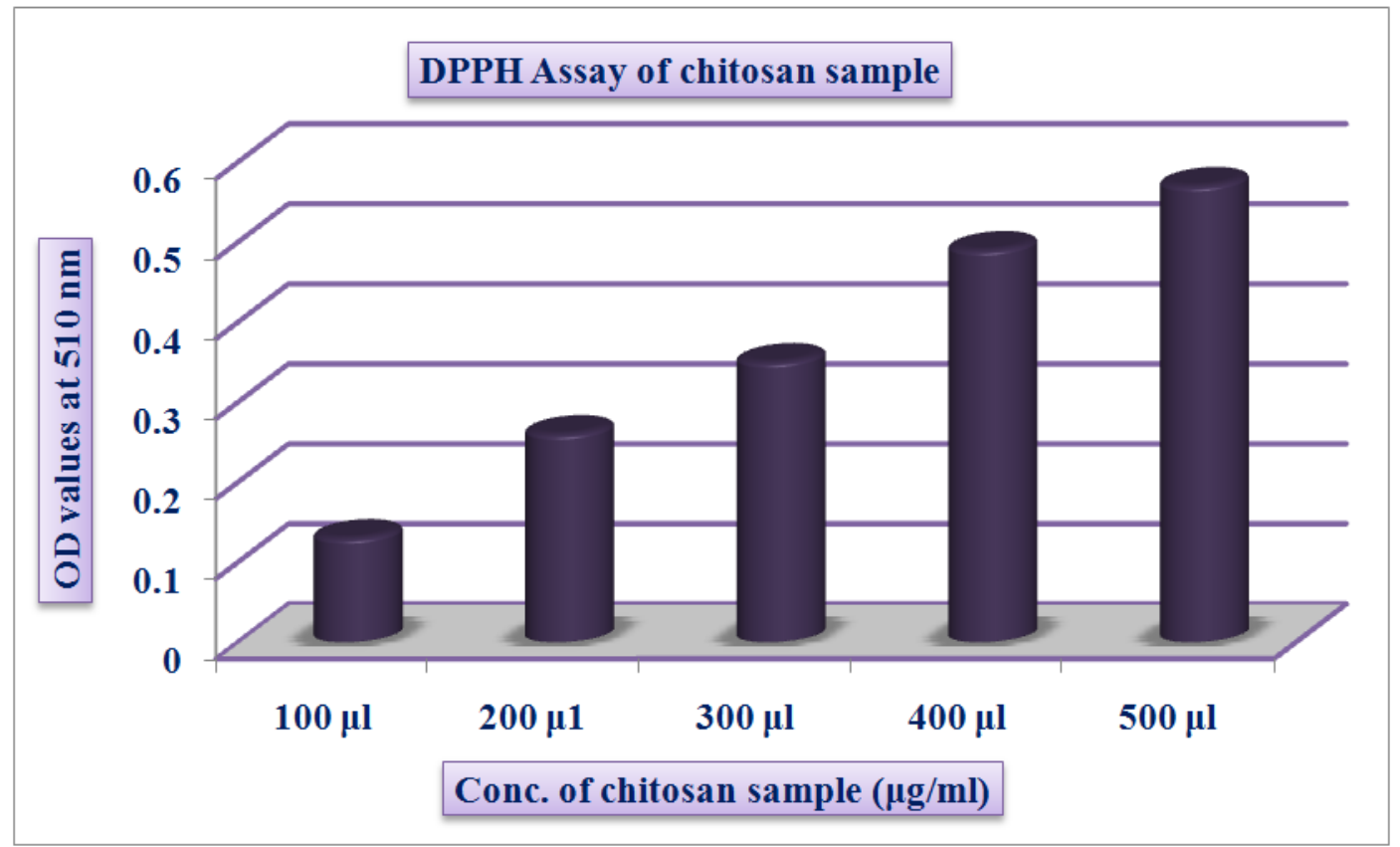


The antifungal activity of chitosan against Colletotrichum gloeosporioides, which causes anthracnose in papaya was studied by Bautista-Banos et al., (2003).

It has been shown that culture broth of Bacillus subtilis grown in the presence of chitin exhibited antifungal activity on pathogenic Fusarium oxysporum, indicating that it can be used as a bio-control agent (SanLang et al., 2002).

\section{Antioxidant property of Prawn Shell Chitosan by DPPH Assay}

The different concentration of prawn shell chitosan was tested against DPPH to find the radical scavenging activity. Free radical scavenging activity of prawn shell chitosan gradually increased with increase in the concentration of chitosan.

Antioxidant activity of prawn shell chitosan was found to be maximized at the concentration of $500 \mu \mathrm{l} / \mathrm{ml}$ (Fig 2). Chitin and its derivatives have been reported to have antioxidant properties (Ngo et al., 2009).

The balance between oxidant formation and antioxidant defense in biological systems is important in order to prevent oxidation of biomolecules.

The higher oxidation activity in cells, which leads to a higher potential for cell injury, is the cause of cancer, arthritis, neurodegeneration and aging (Calabrese et al., 2005).

\section{References}

Ahamed, M.I.N,, N. Gomathi, V. Ragul, M. Priya, R. Priya, Thenmozhi, R.S. Rumaan, V.M. Tariq and N.S. Ahmed (2018). Novel preparation of chitosan from crab shell using probe sonicator and its antibacterial activity. J. Acad. Indus. Res., 6(8):133-136.
Ahmed. S and S. Ikram (2015). Chitosan and its derivatives: A review in recent innovations. Int. J. Pharmaceutical Sci. Res., 6(1):14-3

Anand, M., P. Sathyapriya, M. Maruthupandy and A.H. Beevi (2018). Synthesis of chitosan nanoparticals by TPP and their potential mosquito larvicidal application. Fron. Lab. med., 2(2) :72-78.

Babel, S. and T. A. Kurniawan (2003). Lowcost adsorbents for heavy metals uptake from contaminated water: a review. J. Hazard. Mater. 97:219-243.

Bautista-Baños, S., M. Hernández-López, E. Bosquez-Molina and C.L. Wilson (2003). Effects of chitosan and plant extracts on growth of Colletotrichum gloeosporioides, anthracnose levels and quality of papaya fruit. Crop. Prot., 22: 1087-1092.

Calabrese, V., R. Lodi, C. Tonon, V. D'Agata, M. Sapienza, G. Scapagnini, A. Mangiameli, G. Pennisi, A.M.G. Stella and D.A. Butterfield (2005). Oxidative stress, mitochondrial dysfunction and cellular stress response in Friedreich's ataxia. J. Neurol. Sci., 233: 145-162.

Doares, S. H., T. Syrovets, E. W. Weiler, and C. A. Ryan (1995). Oligogalacturonides and chitosan activate plant defensive genes through the octadecanoid pathway. Proc. Natl. Acad. Sci. USA., 92:40954098.

Goy, R.C, D.D. Britto, O.B.G. Assis (2009). A review of antimicrobial activity of chitosan. Polimeros., 19(3):241-247.

Kim, J.Y., K.N. Kim, J.G. Kim, S.C. Kim S.C, W.J. Leel and C.G. Hyun (2009). In vitro antimicrobial and antioxidant activities of chitosan oligosaccharides. J. Appl. Biol. Chem., 52(2):84-87

Li, B., X. Wang, R. Chen, W. Huangfu and G. Xie (2008). Antibacterial activity of chitosan solution against Xanthomonas pathogenic bacteria isolated from Euphorbia pulcherrima. Carbohydr. 
Polym., 72 : 287-292.

Madhavan, P. and K. Nair (1974). Utilization of prawn waste: Isolation of chitin and its conversion to chitosan. Fish. Technol., $11: 50-53$.

Muzzarelli, R., R. Tarsi, O. Filippini, E. Giovanetti, G. Biagini, and P.E. Varaldo (1990). Antimicrobial properties of $\mathrm{N}$ carboxybutyl chitosan. Antimicrob. Agents Chemother. 34:2019-2023.

Ngo, D.N., S.H. Lee, M.M. Kim and S.K. Kim (2009). Production of chitin oligosaccharides with different molecular weights and their antioxidant effect in RAW 264.7 cells. J. Funct. Foods., 1: 188-198.

Peter, M. G. (1997). Introductory remarks. Carb. Eur. 19:9-15.

Raafat, D., K. von Bargen, A. Haas and H. G. Sahl (2008). Insights into the Mode of Action of Chitosan as an Antibacterial Compound. Appl. Environ. Microbiol., 74 (12) 3764 -3773.

Rabea, E.I., M.E.T. Badawy, C.V. Stevens, G. Smagghe and W. Steurbaut (2003). Chitosan as antimicrobial agent: applications and mode of action. Biomacromolecules 4:1457-1465.

Rushender, R.C., N. Madhavieerike, Madhusudhanan and Venugoalaraokonda. In vitro Antioxidant and free radical scavenging activity of
Nympha eapubescens. J. Pharm. Res., 5(7): 3804-3806.

San-Lang, W., I.L. Shih, C.H. Wang, K.C. Tseng, W.T. Chang, Y.K. Twu, J.J. Ro and C.L. Wang (2002). Production of antifungal compounds from chitin by Bacillus subtilis. Enzyme Microb. Technol., 31: 321-328.

Shahidi, F and R. Abuzaytoun (2005). Chitin, chitosan, and co products: chemistry, production, applications, and health effects. Adv. Food Nutr. Res., 49: 93135.

Singla, A. K., and M. Chawla (2001). Chitosan: some pharmaceutical and biological aspects-an update. J. Pharm. Pharmacol. 53:1047-1067.

Takai, K., T. Ohtsuka, Y. Senda, M. Nakao, K. Yamamoto, J. Matsuoka and Y. Hirai (2002). Antibacterial properties of antimicrobial-finished textile products. Microbiol. Immunol. 46:75-81.

Wydro, P., B. Krajewska and K. Ha (2007). Chitosan as a lipid binder: a Langmuir monolayer study of chitosan-lipid interactions. Biomacromolecules., 8:2611-2617.

Young, D.H, H. Kohle and H. Kauss (1982). Effect of Chitosan on Membrane Permeability of Suspension-Cultured Glycine max and Phaseolus vulgaris cells. Plant Physiol., 70: 1449-1454.

\section{How to cite this article:}

Sundaramoorthy, N., G. Ramya, V. Satheeshwari, J. Janani, A. Parkavi, J. Hemapriya and Vijayanand, S. 2021. Evaluation of the Antimicrobial and Antioxidant Efficacy of Biogenic Chitosan synthesized from the Prawn Exoskeleton. Int.J.Curr.Microbiol.App.Sci. 10(01): 36283635. doi: https://doi.org/10.20546/ijcmas.2021.1001.428 